anæsthetic are doubled, and the chances of healing by first intention are diminished.

The approach to the lumbo-sncral roots. - It has usually been advised in dealing with the lumbar and sacral roots to approach them at their point of exit from the dura. But this necessitates the removal of all the lumbar vertebral laminæ. These, on account of their size, their depth, and the thickness of the muscles covering them, are the most difficult to remove. It seems to me that it is much simpler and easier to attack the lower roots at the point where they all lie close together at their origin from the spinal cord. This necessitates a smaller removal of laminæ, because the roots lie crowded close together instead of far apart. It is quite sufficient to take away the laminæ of the eleventh and twelfth dorsal and the first and second lumbar vertebræ to fully expose and resect all the lumbar and sacral roots. The incision is placed higher up in the back in a situation where it is in less danger of being fouled by urine or infected from a bed-sore. The differentiation between the anterior and the posterior roots is much easier at the level of the cord than at the exit from the dura. The only disadrantage of the high attack of the roots is the increased difficulty of identifying the various nerves. This may be overcome by observing that the third sacral root is the last root of any size to be given off from the conus medullaris. This never need be cut for the relief of spasm of the leg muscles because it is associated with the buttocks and perineum only. The root above it-viz., the second sacral-is the first to be divided, and then each alternate root is removed. So long as a good half of the afferent roots in the lumbar and sacral regions are divided the object of the operation is fulfilled, irrespectively of the exact nerves cut. In certain cases-e.g., my fifth case-where the main complaint is due to spasm of a single group of muscles, it would be better, I think, to divide all the posterior roots concerned with that group rather than to take alternate nerves. It was because I failed to do this that the result in the case I refer to was so poor.

The relation of orthopadic operations to nerve-root division. Professor Förster has so clearly indicated the general rules for the selection of cases of spasm suitable for the operation that I will only refer to one point. It has been suggested by some, especially by Biesalski, ${ }^{12}$ that the nerve operation should not be done until every possible attempt has been made by tenotomies and other orthopædic operations to correct the deformities. There are, of course, some slight cases where a simple tenotomy will give great relief, but when there is that excessive spasm which ties up a whole limb in a complicated deformity it seems to me to be useless to expect any good at all from orthopædic operations whilst the spasm remains unabated. Both weight extension and splint treatment are very badly tolerated by patients in whom there is active or painful spasm, whereas if this spasm be first abolished by the nerve operation the ideal conditions of muscular flaccidity and freedom from pain are provided which are so necessary for the correction of deformities.

I wonld briefly summarise my conclusions as follows:-

1. For the relief of pain the operation of posterior nerveroot resection is a somewhat uncertain proceeding. Case which present very great pain without any organic disease are often of a highly neurotic temperament, and their pain seems to have an important psychical element which is not relieved by the operation.

2. For the relief of visceral crises the operation holds out the only prospect of radical cure which we know of at present. Only those cases of this kind are suitable in which all other means of relief have failed, but on the other hand it is important not to wait until the patient has become debilitated by emaciation and morphia.

3. In cases of spasm associated with lesions of the pyramidal tract the operation has its largest field of usefulness. Spasm is in all these cases definitely relieved, and if the pyramidal tract is not wholly severed a great improvement of motility results.

4. The operation causes definite chromatolysis of some of the motor cells in the anterior horn of the segments involved, and this is probably associated with the lessening of motor spasm.

5. By the use of adrenalin injections as a preliminary to

$12 \ddagger$ Biesalski : Munchener Medicinische Wochensehrift, August, 1910, p. 1634 . the operation the procedure becomes an almost bloodless and speedy one.

6. There is no special shock associated with the division of the posterior nerve roots.

7. It is better to perform the whole operation in one stage

8. In dealing with the brachial roots it is best to do a hemi-laminectomy.

9. The lumbo-sacral roots are best approached at their junction with the cord rather than at their point of exit from the dura.

In conclusion, I would express my most sincere thanks to Professor Förster for the inspiration of his work and writings, and especially for his kindness in coming over to London to explain his views and to demonstrate the brilliant results which have been achieved by his initiative. I have also to thank most cordially Dr. A. R. Short for his elucidation of the pathological part of my paper, and Mr. Jackson Taylor for the photographs and slides of the cases which were under his care as my house surgeon.

(Note.-A full list of references may be found at the end of the articles by Professor Förster and Mr. Hey Groves in the Proceedings of the Royal Society of Medicine.)

Bristol.

\section{NOTE ON THREE CASES OF FIBROID TUMOUR OF THE UTERUS SPONTANEOUSLY FATAL.}

\author{
BY ARTHUR H. N. LEWERS, M.D. LOND., \\ F.R.C.P. LOND.,
}

SENIOR OBSTETRIC PHYSICIAN TO THE IONDON HOSPITAL.

IN considering the line of treatment to be adopted in cases of uterine fibroids, it should be borne in mind that although, as a rule, these tumours for the most part grow slowly, there may, nevertheless, even after many years of quiescence, come an acute or subacute stage which may have a fatal termination, as in the cases here recorded. The life-history of these growths may extend over many years; therefore, if left to run their natural course, it rarely happens that one observer can see the whole progress of a case of fibroids from the time when the tumours are first recognised, or first produce symptoms, to the end of the case, apart from operation.

While, as has been said, fibroids, on the whole, are characterised by slow growth, often with intervals during which they appear to be stationary, they may at times take on changes, whether of degeneration and infection, or of growth, which rapidly cause acute symptoms, and may put the patient's life in jeopardy. Such an acute crisis may easily happen in a patient known to have had fibroids for many years, but it is quite likely that when the acute crisis does occur she may not come under the observation of the practitioner, or practitioners, who have seen her during the earlier period of the case. Those who have happened to have seen the case only during its quiescent and apparently harmless phases may never know what the termination has been, and if they happen to bear the case in remembrance at all may think of it as an example of the satisfactory results of expectant treatment.

Reflections of this kind are suggested by such cases as the three about to be recorded. In each of them the tumours must have been present for many years, and during the greater part of the time presumably symptoms were either absent or slight. Similarly, during the greater part of the time the general health was not seriously affected, and the tumours might no doubt have been removed at a very slight risk. While I do not advocate removing fibroids of the uterus when they are really small, and causing no symptoms, I do think that once they have reached a size equal to that of the pregnant uterus at the end of the third month, for instance, even apart from any marked symptoms, it is safer for the patient to have the growths removed. The popular impression that these tumours may be expected to give no trouble after the menopause is certainly often wrong. Quite recently, for instance, a patient, 65 years of age, was admitted under my care into the London Hospital suffering from metrorrhagia and other symptoms. On dilating the cervix a submucous fibroid of the size of an orange was found in the uterine cavity. It was removed by cutting it away piecemeal, 
and the patient did well. I have seen many other cases several small ulcerated areas, which have encroached on the where serious symptoms have been caused by fibroids long after the menopause.

CASE 1. Case of fibroid spontaneously fatal from hemor. source of the hæmorrhage There is no marked myocardial rhage.-The patient was a married woman, aged 47, who degeneration, in spite of the grave general anæmia. With had had three children, the

last in 1895, and who was admitted under my care into the London Hospital on April 4th, 1908. Up to two years previously the catamenia had been regular and normal ; since that time the periods had been more frequent and profuse. The patient was admitted from the out-patient department, where she had come com plaining of flooding and fainting attacks for the previous three days. During vaginal examination in the out-patient department a severe hæmorrhage occurred, necessitating i $\mathrm{mm}$ ed $\mathrm{i}$ a t $\mathrm{e}$ plugging of the vagina with gauze before the patient could be removed into the wards, where she was admitied at 4 P.M. At 8 P.M. on the same night the gauze plugging was gently removed. A fresh alarming hæmorrhage started. The vagina was again plugged, but the patient never recovered from the effects of this $\mathbf{h}$ morrhage; she shortly became delirious and died from gradual heart failure secondary to the hæmorrhage on April 8th. As regards the treatment adopted after her admission, saline injections per rectum were given freely, but they proved useless.

FIG. 1.

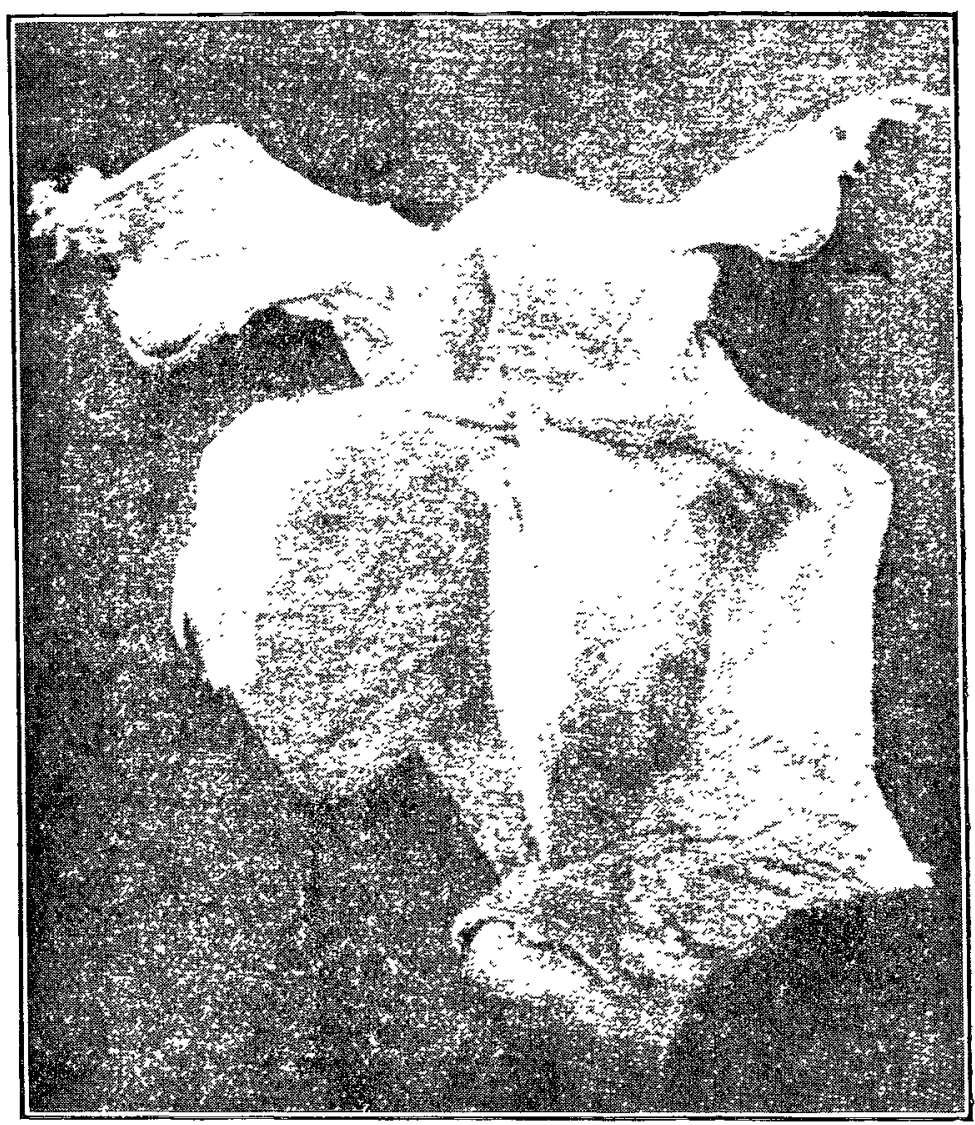

Fiłroid polyp springing from anterior lip of cervix. Fatal hamorrhage. Vagina opened posteriorly. Case 1 .

FIG, 2 the exception of cedema of the lower lobes of the lungs and some muco-purulent secretion in the bronchioles, there are no other outstanding pathological lesions of importance.

CAsE 2. Case of fibrois spontaneously fatal from pulmonary embolism. - The patient, a single woman, aged 42 , was admitted into the London Hospital under my care on June 25th, 1909 . She complained of a Iump in the abdomen which she had noticed for 18 months, and which had been slowly growing; also of micturition being frequent, and on two occasions there had been actual retention. There was said to have been no menorrhagia. The patient was somewhat anæmic. On examination there was a firm median swelling in the hypo gastric region, which could not be separated from the uterus on bimanual examination, and was taken to be the uterus enlarged by fibroids. The patient seemed to be in fair general health on admission, except for the slight anæmia and the presence of the tumour. On the day following admission she was said to have had a kind of "fit." She became suddenly rigid and cyanosed, and fell back dead. She was quietly reading in bed at the time when the seizure occurred.

Post-mortem examination. - This showed the uterus to be considerably enlarged by an interstitial fibroid in the anterior wall forming the hypo gastric "tumour" found on examina tion. It measured 7 inches in diameter and had a circumference of 20 inches. The fibroid was soft and of a beefy - red colour, a n example of "red" degenera. tion. The cause of death was found to have been pulmonary embolism. A lam nated friable clot, 2 inches in length, was found blosking the pul

Fibroid of anterior wall of uterus and cerrix. Treters dilated by pressure. Severe hemorrhage; sudden death, probably partly due to uræmia, Case 3 .

blosking the pulap posteriorly is seen the exieraal

os, the posterior lip of the cervix being thin and crescentic. monary artery at its bifurcation and extending a short On section, the tumour shows well-defined white fibrous way along the left pulmonary artery. The clot was
strands and reddish-brown areas enclosed between them. found to have originated on a valve at the $\epsilon$. A capsule is distinctiv seen loosely attached to the surface left iliac vein, where an adherent grey clot was found of the tum: ur. At its lower vaginal pole the capsule shows filing the lumen of the ressel and extending a quarter of an 
inch in the direction of the blood stream. Both ureters treated with saline injections per rectum, 1.0 with were dilated so as to be half an inch in diameter. The coffee and brandy per rectum, but she die on the pelvis of each kidney was also largely dilated. $\quad$ same evening. No homorrhage had occurred since

CASE 3. Case of large interstitial fibroid of the uterus; / her admission into the hospital. sudden collapse, heart failure, and death.-The patient, a widow, aged 41 , was admitted under my colleague,

Dr. F. J. Smith, on the morning of Jan. $28 \mathrm{th}$, 1910. She had had one child eight years ago. History: She had had a severe flooding in June, 1909, and bleeding had continued on and off, clots occasionally being passed, till Jan. 24th, 1910. On this day, while at the sewing-machine, a severe looding came on. The medical man who was sent for to see her advised her immediate removal to the London Hospital. On admission she was very much collapsed, but was temporarily revived by saline injections and strychnine hypodermically. A catheter specimen of the urine was examined, and contained no albumen. On the afternoon of the 28th I was asked to see her. She was so much collapsed that anything like a com. plete examination of the case was impossible, but a large tumour was noticed in the abdomen reaching considerably above the ambilicus. She was transferred to the gynæcological ward at 7.45 P.M. on the same

FIG. 3.

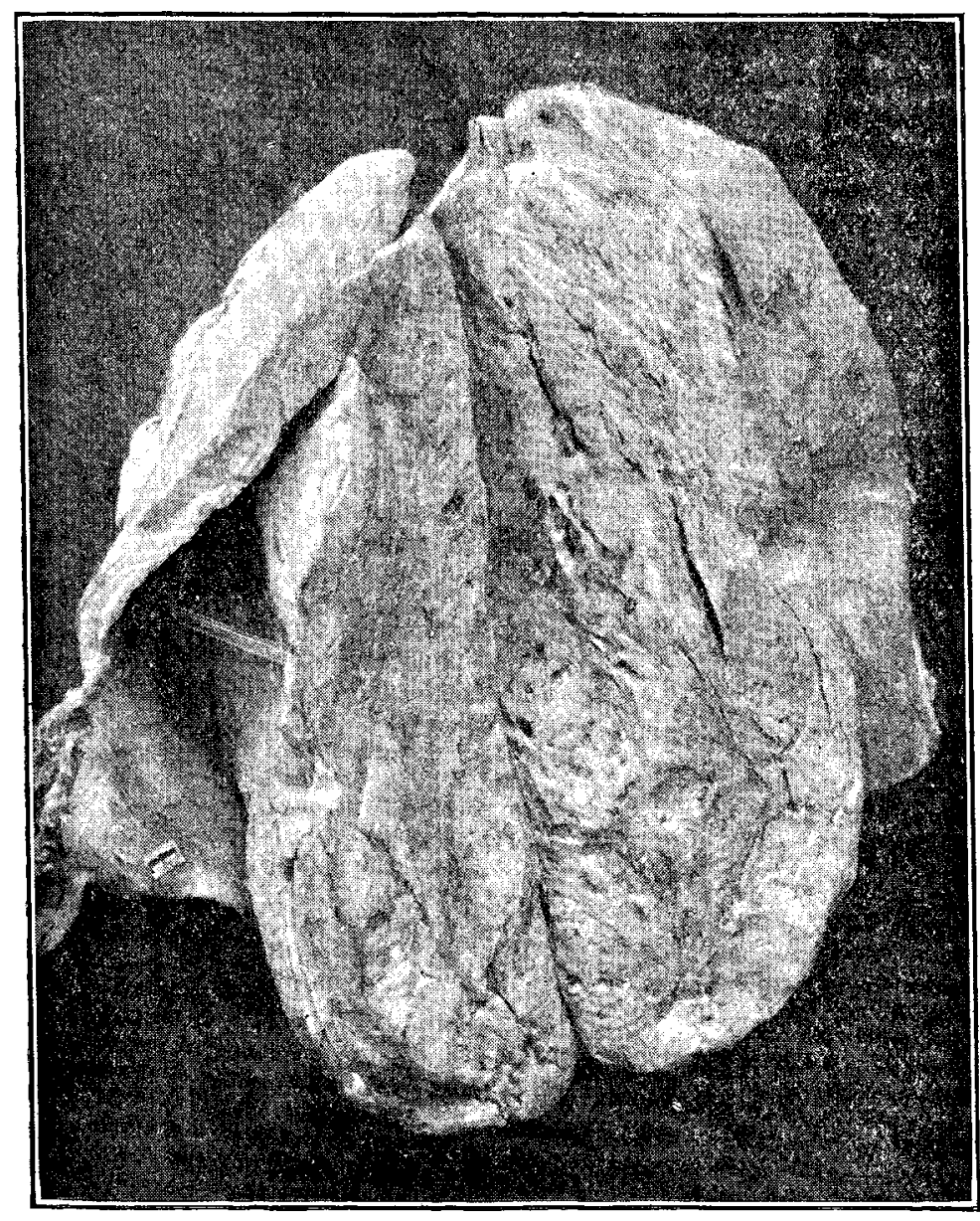

Uterus opened, showing fibroid (in section) springing from anterior wall of uterus and cervix. Cterine carity seen to the lett was seven inches long. Case 3.

Post-mortem examination.-A large fibroid tumour lies in the anterior wall of the uterus and cervix; its lower pole is impacted in the pelvis, its upper pole rises several inches above the umbilicus; the terminal two inches of each ureter are seen firmly compressed between the fibroid behind and the bony wall of pelvis in front. (Figs. 2 and 3.) Above this point the ureters are tortunus, and dilated to the calibre of the forefinger. The pelves of both kidneys are thin and dilated, and both kidneys are hydronephrotic. There are extreme anæmia and cdema of both kidneys. The bladder is very slightly dilated; its base is thin. The majority of the muscle is drawn up and retracted to the fundus of the bladder. The ureters are easily canalised at their terminal portions by a fairly large probe. On the left side there is a small bæmato. salpinx. The right and left ovaries are atrophied, with a small hæmorrhagic cyst in the left ovary. There are some chronic fibrotic tubercles in both apices with evening. The pulse then was very weak and running.|caseous nodules; fibrous adhesions are present over the She was profoundly anæmic, and respiration was whole of the left lung and at the right apex. There are sighing. At 8.30 her condition became very much anæmia and œedema of all the organs.

worse, and her pulse was then uncountable. She was Upper Brook-street, $W$.

THE THERAPEUTIC EFFECTS OF CAR-

\section{BON DIOXIDE SNOW. METHODS} OF COLLECTING AND APPLYING IT.

BY J. HALL-EDWARDS, L.R.O.P. EDIN., HoN. F.R P.S., SENIOR OFFICER IN CHARGE OF THE $X$ RAY DEPARTMENT AT THE GENERAL HOSPITIL, XIRMINGHAM.

For some years liquid air has been used as a local destructive agent by dermatologists, especially in America. The possibility of using it with good effect in surgery early presented itself to the minds of many surgeons who were aware of its properties, but until within the last few years the difficulty of obtaining and transporting it has stood in the way of its general use. It has been successfully used in the treatment of warts, nævi, and angiomata, also in cases of lupus vulgaris, chronic eczema, and lichen planus. Owing to the great rapidity with which liquid air evaporates when exposed to the atmosphere it can be carried about only in especially constructed vessels which cannot be corked or stoppered or they would burst from the internal pressure set up in them. These vessels, the walls of which are composed of two thicknesses of glass with a space between them from which the air has been exhausted, are known as Dewar's or, more popularly, Thermos flasks. The liquid is difficult to apply to small areas, and considerable skill and practice are necessary to limit its $\in$ ffects to the area required. It produces an intense cold, reaching as low as $120^{\circ} \mathrm{C}$. below zero. It was first used in this country by the late Dr. Radcliffe Crocker, who published details of a large number of cases which he had treated with excellent results.

In 1908 Dr. Allen Pusey, of Chicago, suggested the use of carbon dioxide snow in its place, as being far more easily manipulated and applied. The fact that the temperature of the snow is nothing like so low as that of liquid air, conpled with the fact that it can be collected with ease and carried about with little trouble, should commend it to those who require such an agent. With the snow properly prepared a temperature of $79 \circ \mathrm{C}$. below zero can be obtained. This temperature is sufficiently low for the majority of cases. It has been found a very valuable local destructive agent, and has been applied in a large number of dermatological conditions with good effect. The chief merit of carbon dioxide snow lies in the fact that the materials and apparatus for preparing, collecting, and applying it can be always kept ready at hand, whilst its preparation occupies but a few minutes and its cost is small. The principle involved in its use is that of destroying the tissue cells by freezing, the effects being attributed to the exceedingly low temperature obtained. It is said that carbon dioxide has no local action of its own. The freezing of the skin gives very little pain, certainly not more than can be borne by the average individual, and frequently children bear it without complaint. The immediate effect of the application of the snow is the formation of a hard, white area, corresponding in size to the piece of compressed snow applied. This area is, as 